\title{
ASPECTS correlates with Scandinavian Stroke Scale for predicting early neurological impairment
}

\author{
Correlação do ASPECTS com a escala Escandinava de AVC para predizer comprometimento \\ neurológico precoce
}

Gustavo José Luvizutto', Maicon Gonçalves Gabriel', Gabriel Pereira Braga', Thiago Dias Fernandes', Luiz

Antônio de Lima Resende1, Octávio Marques Pontes-Neto², Rodrigo Bazan ${ }^{1}$

\begin{abstract}
Objective: To investigate the correlation between the Alberta Program Early CT Score (ASPECTS) and the Scandinavian Stroke Scale (SSS) for the evaluation of neurological impairment in patients with acute stroke. Method: 59 patients with a first acute ischemic stroke were evaluated. The ASPECTS were evaluated by 2 neurologists at admission and by another neurologist after 48 hours. The NIHSS and SSS was applied to determinate stroke severity. Correlations and agreements were analysed statistically by Spearman and Kappa tests. Results: ASPECTS was correlated with National Institute of Health Stroke Scale (NIHSS) at admission $(r=-0.52 ; p<0.001)$ and SSS $(r=0.50$; $p<0.001)$. The ASPECTS and SSS items were most correlated with arm $(r=0.52 ; p<0.001)$ and hand $(r=0.49 ; p<0.001)$ motor power, and speech $(r=0.51 ; p<0.001)$. The SSS of 25.5 shows sensitivity $(68 \%)$ and specificity $(72 \%)$ when associated with ASPECTS $\leq 7$. Conclusion: The SSS can predict worst neurological impairment when associated with lower values of ASPECTS.
\end{abstract}

Keywords: stroke, neuroimaging, outcome measures, scales.

\section{RESUMO}

Objetivo: Investigar a relação entre o Alberta Program Early CT Score (ASPECTS) e a Scandinavian Stroke Scale (SSS) para avaliação da incapacidade neurológica de pacientes na fase aguda do acidente vascular cerebral (AVC). Método: 59 pacientes com diagnóstico de primeiro AVC foram avaliados. O ASPECTS foi avaliado por 2 neurologistas na admissão e por outro neurologista após 48 horas. 0 National Institute of Health Stroke Scale (NIHSS) e SSS foram aplicadas para determinar a gravidade do AVC. As correlação e concordâncias foram analisadas estatisticamente pelos testes de Spearman e Kappa. Resultados: ASPECTS foi correlacionado com o NIHSS na admissão $(r=-0,52 ; p<0,001)$ e SSS $(r=0,50 ; p<0,001)$. O ASPECTS e os itens do SSS que mais se relacionaram foram força do braço $(r=0,52$; $p<0,001)$, da mão $(r=0,49 ; p<0,001)$ e fala $(r=0,51 ; p<0,001)$. A pontuação da SSS de 25,5 mostrou sensibilidade (68\%) e especificidade (72\%) quando associado ao ASPECTS $\leq 7$. Conclusão: A SSS pode predizer pior incapacidade neurológica quando associado a baixos valores do ASPECTS.

Palavras-chave: acidente vascular cerebral, neuroimagem, medidas de desfecho funcional, escalas.

In Brazil as well as worldwide, stroke is among the leading causes of the functional disability and death in the adult population $^{1,2,3,4,5}$. The increasing importance of imaging studies in recent years has led to the appearance of objective scales for evaluation of severity, such as the Alberta Program Early CT Score (ASPECTS), which subdivides the territory of the middle cerebral artery (MCA) into ten standardized regions evaluated by cranial $\mathrm{CT}^{6,7}$.
The ASPECTS is a precise and practical method for evaluating stroke in the acute phase and is indicated especially in the first 6 hours after the initial event to detect early changes in the hyperacute phase and predict the possibility of haemorrhagic transformation, by outlining the severity of the ischemic area ${ }^{8,9,10}$. Recently we validated the SSS for the Brazilian population and found it useful for evaluating severity in stroke patients in our country ${ }^{11}$. This study aimed to investigate the

${ }^{1}$ Universidade Estadual Paulista “Júlio de Mesquita Filho", Faculdade de Medicina de Botucatu, Departamento de Neurologia, Psicologia e Psiquiatria, Botucatu SP, Brazil;

${ }^{2}$ Universidade de São Paulo, Faculdade de Medicina de Ribeirão Preto, Departamento de Neurociências e Ciências do comportamento, Ribeirão Preto SP, Brazil. Correspondence: Gustavo José Luvizutto; Universidade Estadual Paulista, Faculdade de Medicina de Botucatu; Av. Prof. Montenegro, s/n - Distrito de Rubião Junior; 18618-970 Botucatu SP, Brasil; E-mail: gluvizutto@fmb.unesp.br

Conflict of interest: There is no conflict of interest to declare.

Received 06 October 2014; Received in final form 09 January 2015; Accepted 29 January 2015. 
correlation between the ASPECTS and the Scandinavian Stroke Scale (SSS) to evaluate the severity of neurological deficit in Brazilian patients with acute stroke involving the middle cerebral artery (MCA), to relate each item on the SSS scale with ASPECTS and to identify whether there is some cutoff value of SSS that maximizes the sensitivity and specificity of the severity in a worst neurological impairment. The first hypothesis of the study is that lower values of ASPECTS are positively correlated with lower SSS values, especially with specific items from the scale that evaluates the MCA territory.

\section{METHOD}

The study is a prospective series of cases that includes 59 individuals, of both sexes, admitted to the Stroke Unit of the Botucatu Medical School in the period from March to December of 2012 with a diagnosis of ischemic stroke - confirmed by clinical examination and noncontrast CT scan - in middle cerebral artery territory confirmed by the classification of $\mathrm{BAMFORD}^{12}$, and excluding patients with ischemic stroke in the anterior or posterior cerebral artery territory, haemorrhagic stroke, prior stroke, presenting a modified Rankin Scale (mRS) score prior to admission $\geq 1$, previous diagnosis of dementia or patients that were eligible for and received any type of treatment by cerebral reperfusion therapy (intra-arterial or intravenous).

At the admission in the stroke unit, the first procedure was clinical attention by means of neurological examination and National Institutes of Health Stroke Scale (NIHSS) by neurovascular physician of the Stroke Unit; then a noncontrast CT scan was obtained for clinical procedures and determination of the ASPECTS by 2 neurologists from the stroke team at admission independently. The new evaluation was applied after 48 hours by another expert neurologist to determine the neurological impairment severity through $\mathrm{NIHSS}^{13}$, and the quantitative severity of paralysis and incapacity according to SSS ${ }^{11}$. These scales were applied without knowledge of the previous ASPECTS value at admission and performed by a neurologist certified in these scales. The study was approved by the Ethics Committee on Human Research of our Institution and all the patients or their guardians signed terms of free and informed consent to be included.

\section{Statistical analysis}

The concordance between the 2 neurologists for ASPECTS scoring at admission was evaluated by the Kappa coefficient. The relation among SSS, NIHSS and ASPECTS was assessed by the Spearman correlation and linear regression model considering the potential confounders (age, sex, topography of lesion and NIHSS at admission). The test of Shapiro-Wilk was performed to indicate whether the linear regression was adequate. The correlation between the items SSS and ASPECTS was measured by means of the Spearman correlation. The cutoff value of SSS that maximizes the sensitivity and specificity of the severity of the worst neurological impairment was estimated by constructing ROC curves using the ASPECTS. Significance was set at p less than 0.05. Statistical analyses were performed using the software SPSS v.15.0.

\section{RESULTS}

Based on the exclusion criteria, 151 individuals had been excluded from the study: 42 patients received a cerebral reperfusion therapy, 14 presented previous diagnosis of dementia, 28 had a prior stroke, 38 presented haemorrhagic stroke, 8 had an ischemic stroke in posterior cerebral artery territory, 12 had an ischemic stroke in anterior cerebral artery territory and 9 presented a mRS > 1 at admission. The 59 studied patients were comprised of 17 males and 42 females, with mean age of 66 years. The concordance between the 2 neurologists for ASPECTS was - Kappa coefficient $=0.706$; $p<0.001$. The ASPECTS values ranged from 5 to 10 (median $=9$ ), NIHSS varied from 0 to 25 (median $=8$ ); after 72 hours the NIHSS values ranged from to 0 to 31 (median $=6$ ), while SSS varied from 4 to 58 (median = 34). At admission, the higher the ASPECTS, the lower the NIHSS values, $-r=-0.56$. After 48 hours the ASPECTS score was negatively correlated with NIHSS (-0.52) but positively related to SSS $(r=0.50)$.

Table 1 shows that ASPECTS accounts for $63.5 \%$ of the SSS variability. For each unit of increase in ASPECTS, there is a corresponding rise of 1.57 points in the SSS median considering the potential confounders. The $p$-value $(p=0.17)$ obtained by the Shapiro-Wilk test signifies that the adjustment was appropriate.

The correlations between ASPECTS and SSS items (Table 2) were assessed for consciousness ( $r=0.23$; $p=0.082)$, eye movements $(r=0.23 ; p=0.074)$, arm motor power $(r=0.52$; $\mathrm{p}<0.001)$, hand motor power $(\mathrm{r}=0.49$; $\mathrm{p}<0.001)$, leg motor power $(r=0.33 ; p=0.010)$, orientation $(r=0.28 ; p=0.031)$, speech $(r=0.51 ; p<0.001)$, facial palsy $(r=0.21 ; p=0.108)$, gait $(r=0.18 ; p=0.167)$ and maximal score $(r=0.50 ; p=0.001)$.

The Scandinavian Stroke Scale score of 25.5 shows sensitivity and specificity of $68 \%$ and $72 \%$, respectively, when associated with ASPECTS $\leq 7$ for the worst neurological impairment (Figure 1). Among the items on the Scandinavian Stroke Scale, speech presented sensitivity and specificity, respectively, of $72 \%$ and $78 \%$ (Figure 2).

\section{DISCUSSION}

In the present study, the ASPECTS values have demonstrated a closer association with the severity scales to identify neurological deficit and acute-phase outcome. The medical literature reports that low ASPECTS values were correlated with a high NIHSS score and a reduced long-term functional capacity ${ }^{14,15,16}$. 
Table 1. Adjusted regression model to explain the median SSS score as a function of the ASPECTS score considering the potential confounders.

\begin{tabular}{lccccc}
\hline Variable & $\beta$ & ep & $p$ & \multicolumn{2}{c}{$95 \%$ IC } \\
\hline Constant & 33.14 & 12.61 & 0.013 & 7.45 & 58.83 \\
ASPECTS & 1.57 & 1.03 & 0.136 & -0.52 & 3.66 \\
Age (years) & -0.09 & 0.12 & 0.469 & -0.33 & 0.15 \\
Sex (male) & 5.74 & 3.30 & 0.091 & -0.98 & 12.46 \\
Topography (left side) & 5.44 & 3.39 & 0.118 & -1.46 & 12.34 \\
NIHSS at admission & -1.61 & 0.29 & 0.000 & -2.19 & -1.03 \\
\hline
\end{tabular}

$\mathrm{R}^{2}=63.5 \%$; Residue analysis: $\mathrm{p}=0.178$ (Shapiro-Wilk); ASPECTS: Alberta Program Early CT Score; SSS: Scandinavian Stroke Scale; NIHSS: National Institute of Health Stroke Scale.

Table 2. Correlation between ASPECTS scale score and SSS items in acute phase of stroke.

\begin{tabular}{llcc}
\hline Scale & Items & $r$ & $p$-value \\
\hline SSS & Consciousness & 0.23 & 0.082 \\
& Eye movements & 0.23 & 0.074 \\
& Arm, muscular strength & 0.52 & 0.000 \\
& Hand, muscular strength & 0.49 & 0.000 \\
Leg, muscular strength & 0.33 & 0.010 \\
Orientation & 0.28 & 0.031 \\
Speech & 0.51 & 0.000 \\
Facial paralysis & 0.21 & 0.108 \\
& Movement & 0.18 & 0.167 \\
& Total score & 0.50 & 0.000 \\
\hline
\end{tabular}

SSS: Scandinavian Stroke Scale; ASPECTS: Alberta Program Early CT Score; r: Spearman correlation.

The kappa coefficient presented between the two neurologists in our study shows moderate results. The interagreement concordance values of ASPECTS change with a clinical experience, but is highly recommended for the clinical practice in neurovascular ${ }^{8}$. In study to analyses the interagreement confiability of ASPECTS to intra-arterial stroke treatment selection, the coefficient of correlation was 0.77 , and when ASPECTS was dichotomized in $\leq 7$ or $>7$, the value was $0.53^{17}$. These findings suggest that the ASPECTS is dependent evaluator and the concordance rate in our study is in agreement with the international studies.

The NIHSS is the principle scale utilized in the acute phase for its specific items that define the neurological severity and predict the prognosis starting at the admission of the patient ${ }^{7,13}$. In our study, we observed a strong association between the ASPECTS scores and NIHSS values at admission into the stroke unit, which reflects the relation between the ischemic area and severity of neurological deficit.

Diverse authors report that ASPECTS is closely associated with the functional outcome of the dichotomous approach (> 7 vs. $\leq 7$ ), having limited performance when only its value is evaluated in isolation to define the prognosis ${ }^{7}$. In our study, we observed a mild association between ASPECTS values and the scales of evaluation the neurological impairment in the acute phase of stroke ${ }^{18,19}$. For each ASPECTS score increase at hospital admission, there was a 1.5-point

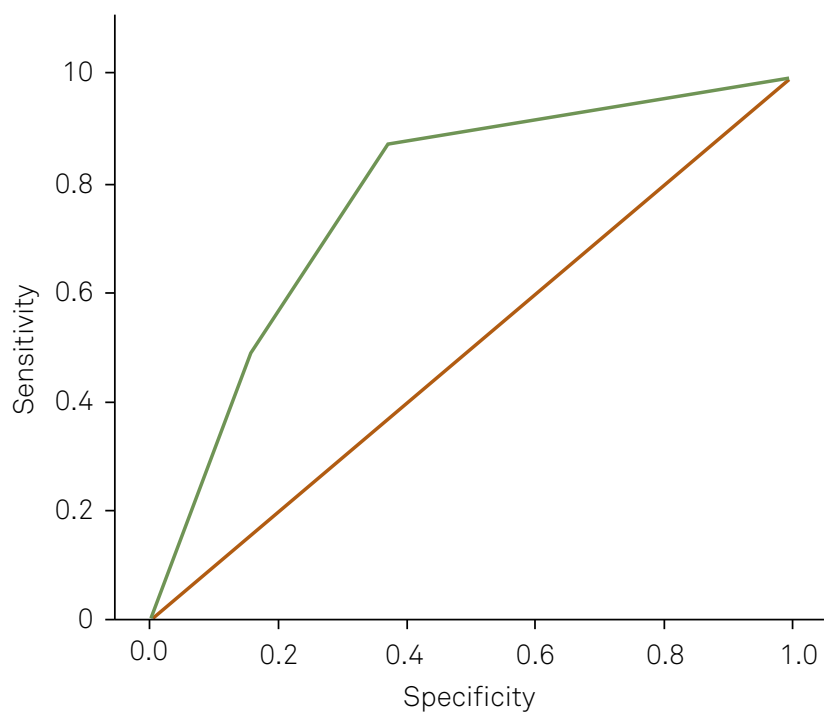

Figure 1. Sensitivity and specificity of total Scandinavian Stroke Scale score with ASPECTS values.

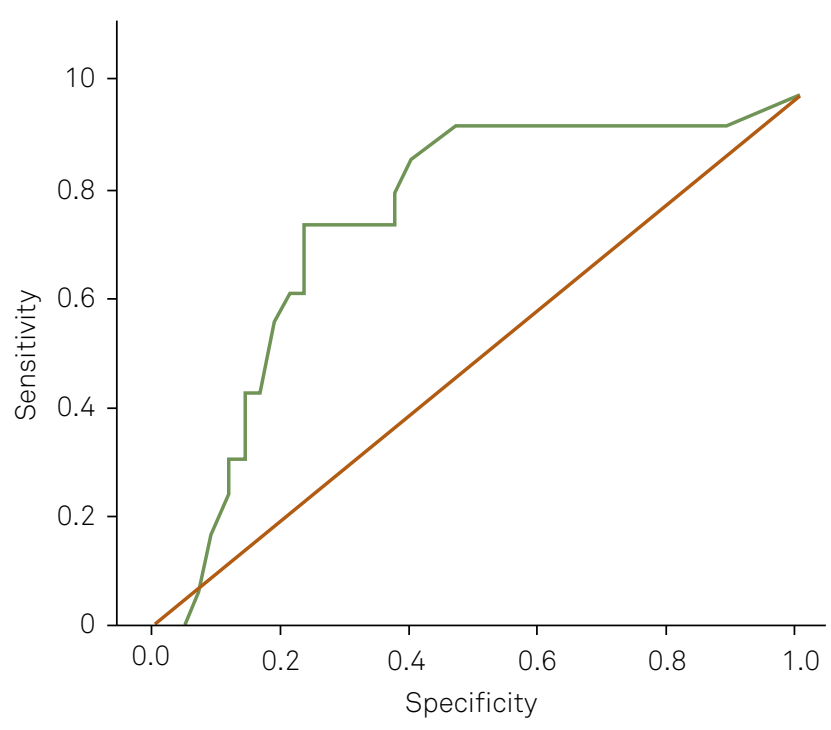

Figure 2. Sensitivity and specificity of speech item on Scandinavian Stroke Scale with ASPECTS values.

improvement in SSS, a determinative indicator in the neurological impairment after the acute phase of stroke.

The highest correlation of ASPECTS with the SSS items was with the upper limbs (strength of the arm and hand) and speech. Diverse studies emphasize that the territory irrigated by the MCA presents greater cortical representation for the hand and speech, given that brachial paresis, global aphasia and comprehension disorders are found with greater frequency in infarcts in these territories ${ }^{20,21}$.

The SSS is currently utilized to predict the severity of the neurological impairment ${ }^{22,23,24}$. When ASPECTS was associated with total SSS score, it was observed that the values below 25.5 presented higher sensitivity and specificity for scores $\leq 7$, a finding demonstrating that values below this endpoint should not be considered alarming from the neurological and 
functional point of view, with this association being demonstrated in a manner unreported by the literature.

Limitations arising in our study included not delimiting confounding factors for acute-phase outcome such as levels of glycaemia and haemoglobin, as well as its small sample size of patients. Despite the limits of the study, ASPECTS represents a useful system for detecting the ischemic area, besides being a consistent predictor of prognosis. Given that cranial tomography is performed in Brazil and several other countries on the majority of acute-phase stroke patients, ASPECTS must be proposed as a tool for objective evaluation due to its low cost and high benefit. However, we emphasize the need for extensive training with the scales and the interpretation of images by the stroke team.

In conclusion, the Scandinavian Stroke Scale showed better sensitivity and specificity when associated with lower values of ASPECTS, especially in speech, for predicting worst early neurological impairment, while the SSS demonstrated correlation with speech and upper-limb functions during the acute phase of a stroke involving the middle cerebral artery.

\section{References}

1. Go AS, Mozaffarian D, Roger VL, Benjamin EJ, Berry JD, Borden WB et al. Heart Diseases and Stroke Statistics - 2013 Update: a report from the American Heart Association. Circulation. 2013;127(1):e6-245. http://dx.doi.org/10.1161/CIR.0b013e31828124ad

2. Lotufo PA, Benseñor IM. Trends of stroke subtypes mortality in Sao Paulo, Brazil (1996-2003). Arq Neuropsiquiatr. 2005;63(4):951-5. http://dx.doi.org/10.1590/S0004-282X2005000600009

3. Langhorne P, Coupar F, Pollock A. Motor recovery after stroke: a systematic review. Lancet Neurol. 2009;8(8):741-54. http://dx.doi.org/10.1016/S1474-4422(09)70150-4

4. Nichols-Larsen DS, Clark PC, Zeringue A, Greenspan A, Blanton S. Factors influencing stroke survivors' quality of life during subacute recovery. Stroke. 2005;36(7):1480-4. http://dx.doi.org/10.1161/01.STR.0000170706.13595.4f

5. Saposnik G; Del Brutto OH. Stroke in South America: A systematic review of incidence, prevalence, and stroke subtypes. Stroke. 2003;34(9): 2103-7. http://dx.doi.org/10.1161/01.STR.0000088063.74250.DB

6. Barber PA, Demchuk AM, Zhang J, Buchan AM. Validity and reliability of a quantitative computed tomography score in predicting outcome of hyperacute stroke before thrombolytic therapy. ASPECTS Study Group. Alberta Stroke Programme Early CT Score. Lancet. 2000;355(9216):1670-4 . http://dx.doi.org/10.1016/S0140-6736(00)02237-6

7. Puetz V, Dzialowski I, Hill MD, Demchuk AM. The Alberta Stroke Program Early CT Score in clinical practice: what have we learned?. Int J Stroke. 2009;4(5):354-64. http://dx.doi.org/10.1111/j.1747-4949.2009.00337.x

8. Pexman JHW, Barber PA, Hill MD, Sevick RJ, Demchuk AM, Hudon ME, et al. Use of the Alberta Stroke Program Early CT Score (ASPECTS) for assessing CT scans in patients with acute stroke. AJNR Am J Neuroradiol. 2001;22(8):1534-42.

9. Lin K, Rapalino O, Law M, Babb JS, Siller KA, Pramanik BK. Accuracy of the Alberta Stroke Program Early CT Score during the first 3 hours of middle cerebral artery stroke: comparison of noncontrast CT, CT angiography source images, and CT perfusion. AJNR Am J Neuroradiol. 2008;29(5):931-6. http://dx.doi.org/10.3174/ajnr.A0975

10. Mak HK, Yau KK, Khong Pl, Ching AS, Cheng PW, Au-Yeung PK et al. Hipodensity of $>1 / 3$ middle cerebral artery territory versus Alberta Stroke Programme Early CT Score (ASPECTS) comparison of two methods of quantitative evaluation of Early CT changes in hyperacute ischemic Stroke in the community setting. Stroke. 2003;34(5):1194-6. http://dx.doi.org/10.1161/01.STR.0000069162.64966.71

11. Luvizutto GJ, Monteiro TA, Braga G, Pontes-Neto OM, de Lima Resende LA, Bazan R. Validation of the scandinavian stroke scale in a multicultural population in Brazil. Cerebrovasc Dis Extra. 2012;2(1):121-6. http://dx.doi.org/10.1159/000345948

12. Bamford J, Sandercock P, Dennis M, Burn J, Warlow C. Classification and natural history of clinically identifiable subtypes of cerebraL infarction. Lancet. 1991;337(8756):1521-6. http://dx.doi.org/10.1016/0140-6736(91)93206-0

13. Cincura C, Pontes-Neto OM, Neville IS, Mendes HF, Menezes DF, Mariano DC et al. Validation of the Natinal Institutes of Health Stroke Scale, modified Rankin Scale and Barthel Index in Brazil: the role of cultural adaptation and structured interviewing. Cerebrovasc Dis. 2009;27(2):119-22. http://dx.doi.org/10.1159/000177918

14. Aviv RI, Mandelcorn J, Chakraborty S, Gladstone D, Malham S, Tomlinson G et al. Alberta Stroke Program Early CT Scoring of CT perfusion in early stroke visualization and assessment. AJNR Am J Neuroradiol. 2007;28(10):1975-80. http://dx.doi.org/10.3174/ajnr.A0689

15. Menon BK, Puetz V, Kochar P, Demchuk AM. ASPECTS and other neuroimaging scores in the triage and prediction of outcome in acute stroke patients. Neuroimaging Clin N Am. 2011;21(2):407-23. http://dx.doi.org/10.1016/j.nic.2011.01.007

16. Alexander LD, Pettersen JA, Hopyan JJ, Sahlas DJ, Black SE. Long-term prediction of functional outcome after stroke using the Alberta Stroke Program Early Computed Tomography Score in the subacute stage. J Stroke Cerebrovasc Dis. 2012;21(8):737-44. http://dx.doi.org/10.1016/j.jstrokecerebrovasdis.2011.03.010

17. Gupta AC, Schaefer PW, Chaudhry ZA, Leslie-Maxwi TM, Chandra RV, González RG et al. Interobserver reliability of baseline noncontrast CT Alberta Stroke Program Early CT Score for intra-arterial stroke treatment selection. AJNR Am J Neuroradiol. 2012;33(6):1046-9. http://dx.doi.org/10.3174/ajnr.A2942

18. Demchuk AM, Coutts SB. Alberta Stroke Program Early CT Score in acute stroke triage. Neuroimaging Clin N Am. 2005;15(2):409-19. http://dx.doi.org/10.1016/j.nic.2005.06.008

19. Demchuk AM, Hill MD, Barber PA, Silver B, Patel SC, Levine SR. Importance of early ischemic computed tomography changes using ASPECTS in NINDS rtPA Stroke Study. Stroke. 2005;36(10):2110-5. http://dx.doi.org/10.1161/01.STR.0000181116.15426.58

20. Oliveira FF, Damasceno BP. A topographic study on the evaluation of speech and language in the acute phase of a first stroke. Arq Neuropsiquiatr. 2011;69(5):790-8. http://dx.doi.org/10.1590/S0004-282X2011000600013

21. Pikula A, Stefanidou M, Romero JR, Kase CS. Pure motor upper limb weakness and infarction in the precentral gyrus: mechanisms of stroke. J Vasc Interv Neurol. 2011;4(1):10-3.

22. Oxbury JM, Greenhall RC, Grainger KM. Predicting the outcome of stroke: acute stage after cerebral infarction. BMJ. 1975;3(5976):125-7. http:// dx.doi.org/10.1136/bmj.3.5976.125

23. Scandinavian Stroke Study Group: Multicenter trial of hemodilution in ischemic stroke: background and study protocol. Stroke. 1985;16(5):885-90. http://dx.doi.org/10.1161/01.STR.16.5.885

24. De Haan R, Horn J, Limburg M, Van Der Meulen J, Bossuyt P. A comparison of five stroke scales with measures of disability, handicap, and quality of life. Stroke. 1993;24(8):1178-81. http://dx.doi.org/10.1161/01.STR.24.8.1178 